(2) Open Access Full Text Article

REVIEW

\title{
New and emerging treatments for ulcerative colitis: a focus on vedolizumab
}

This article was published in the following Dove Press journal:

Biologics:Targets and Therapy

22 May 2013

Number of times this article has been viewed

\section{Tamsin Gledhill' \\ Keith Bodger ${ }^{2}$ \\ 'Digestive Diseases Centre, Aintree University Hospital Trust, ${ }^{2}$ Gastroenterology Department, Institute of Translational Medicine, University of Liverpool, Liverpool, UK}

Correspondence: Keith Bodger Room 3. I4, Clinical Sciences Centre, Aintree University Hospital Trust, Liverpool L9 7AL, UK

Email kbodger@liverpool.ac.uk
Abstract: Ulcerative colitis (UC) is the most common form of chronic inflammatory bowel disease and lacks a curative pharmacological treatment. Traditional therapies, which include 5-aminosalicylates, corticosteroids and immunosuppressants, aim to induce and maintain remission. Biological therapy with anti-tumor necrosis factor-alpha agents has added to the range of available treatments. Vedolizumab belongs to a new class of agents (integrin antagonists) that inhibit leukocyte adhesion and aim to selectively inhibit the inflammatory pathway. This article reviews the emerging data on the use of vedolizumab for UC. Evidence to date supports its efficacy in inducing remission in UC, with no major safety concerns identified.

Keywords: inflammatory bowel disease, effectiveness, integrin antagonists

\section{Introduction}

Ulcerative colitis (UC) is one of two main forms of inflammatory bowel disease (IBD). It affects the colonic mucosa in a continuous distribution from the rectum to a varying extent of the colon. UC is more common than Crohn's disease (CD), with an incidence varying from nine to 20 cases per 100,000 person years and a prevalence of 156-291 cases per $100,000 .^{1}$ Disease activity may be classified simply as mild, moderate, or severe, but clinical trials typically incorporate one of the validated disease-activity indices, which are based on scores for individual symptoms (eg, diarrhea, rectal bleeding, abdominal pain), laboratory parameters, and endoscopic appearances. ${ }^{2}$

\section{Traditional drug treatment}

Standard medical therapy has remained consistent over time: aiming to induce remission, oral or intravenous steroids are used for moderate-to-severe disease flares, whereas first-line treatment for mild-to-moderate disease includes oral and/or topical 5-aminosalycilate (5-ASA) agents and topical steroids. The mainstay of maintenance therapy for UC is 5-ASA formulations with the addition of immunosuppressant medication, such as thiopurines, in cases of relapse or ongoing disease activity. For acute severe (fulminant) disease, systemic glucocorticoids remain first-line, with cyclosporine used in steroid refractory disease to prevent the need for colectomy.

Over the last decade, anti-tumor necrosis factor therapy has been used for moderateto-severe disease, depending on regulatory and funding decisions and local practices. It has become an established "salvage" therapy in the management of acute severe colitis not responding to glucocorticoid therapy. ${ }^{3}$ Infliximab has been shown to be effective in inducing and maintaining remission in UC. ${ }^{4}$ Adalimumab has not had such 
promising results, yet higher doses have been shown to be effective in inducing remission in those not responding to steroids and immunosuppressants. ${ }^{5}$ There is some evidence for maintenance of remission with adalimumab, although this is less convincing with small numbers of patients who have failed treatment with other therapies, including infliximab. ${ }^{6,7}$

With improved understanding of the mechanisms causing inflammation and the development of therapies with alternative modes of action, there may be increasing support for switching to an alternative class of biological therapy in future.

\section{Integrin antagonists}

Integrin antagonists are a class of therapy that incorporates an antibody that blocks the lymphocyte-homing mechanism on T-lymphocytes. The first to be developed was natalizumab. However, the use of natalizumab in patients with CD was halted when this particular $\alpha_{4} \beta_{1}$-humanized antibody resulted in serious adverse events and was withdrawn from use. Natalizumab was reintroduced in the USA with a surveillance program for the management of CD. An integrin antagonist selective to the $\alpha_{4} \beta_{7}$ integrin has been developed and, recently, Phase III trials have reported promising efficacy on the background of safe and well-tolerated therapy. This article will review the evidence produced in the development of this novel therapy in the management of UC.

\section{The role of the $\alpha_{4} \beta_{7}$ integrin in IBD pathogenesis}

In normal mucosa, there is a constant equilibrium between proinflammatory and anti-inflammatory cytokines. Colonic inflammation in IBD reflects the outcome of both a genetic alteration in the innate immune system and the amplified responses of adaptive immunity. The inflammation seen in UC is thought to be associated with disturbance of the homoeostatic balance between regulatory and effector T-cells (eg, T-helper [Th] 1, Th2, and Th17) and an atypical Th2 response mediated by non-classic natural killer T-cells producing interleukin (IL) 5 and IL-13. ${ }^{1}$

IL-13 is important because it exerts cytotoxic functions against epithelial cells, impairing function of the epithelial barrier and inducing apoptosis of the epithelial cells. ${ }^{8}$ The ongoing inflammatory response and activation of T-cells with resulting cytokine production is in part due to the upregulation of the normal lymphocyte-homing response, recruiting high numbers of T-cells to the intestinal mucosa. The $\alpha_{4} \beta_{7}$ integrin is a molecule found on circulating
T-lymphocytes which is involved in the recruitment of leucocytes to the gastrointestinal (GI) tract. ${ }^{9}$

The $\alpha_{4} \beta_{7}$ integrin is activated on the lymphocyte surface membrane and binds with its glycosaminoglycan ligand on the endothelial surface membrane, the mucosal addressincell adhesion molecule-1 (MAdCAM-1). This is selectively expressed on the endothelium of intestinal vasculature, binding lymphocytes from the endothelial lumen as they pass. These bound lymphocytes then migrate into the lamina propria and tissue. Abnormal retention in these cells, forms a critical part of the inflammatory process. The $\alpha_{4} \beta_{7}$ integrin mediates the infiltration of the GI tract by memory T-cells and the MAdCAM-1. An endothelial receptor is believed to contribute to chronic GI inflammation by mediating lymphocyte homing to lymphatic tissues in the Peyer's patches and the recruitment of these cells into the intestine during the process of inflammation. ${ }^{10}$

Studies have shown significantly higher levels of the ligand $\alpha_{4} \beta_{7}$ integrin and MAdCAM-1 in colons of IBD patients than irritable bowel syndrome controls. ${ }^{11}$ The engagement of these molecules is associated with the homing in of gut-associated lymphocytes to areas of inflamed and normal colonic mucosa. ${ }^{12}$ Lower numbers of T-lymphocytes with the $\alpha_{4} \beta_{7}$ integrin have been shown to be circulating in peripheral blood in patients with colonic inflammation. ${ }^{13}$

Mucosal inflammation is associated with enhanced production of macrophage-derived cytokines including tumor necrosis factor (TNF) $\alpha$, IL-1 $\beta$, IL-8, and IL-18. These cytokines continue to drive the inflammatory response and are a major stimulus for synthesis of tissue destructive proteases from stromal cells, leading to ongoing inflammation. ${ }^{14}$

Infliximab and adalimumab, the two biological therapies in routine use in IBD currently, act by neutralizing the TNF- $\alpha$ cytokine. Infliximab is a $75 \%$ human, $25 \%$ murine immunoglobulin (Ig G 1) monoclonal antibody that can induce T-cell apoptosis by complement activation and cytotoxicity. ${ }^{15}$ Infliximab also acts on cell adhesion molecule expression by downregulating vascular cell adhesion molecule-1 (VCAM-1). It also has wider anti-inflammatory effects, including reducing the production of circulating cytokines. Adalimumab is fully human IgG 1 monoclonal antibody binding with high affinity to human TNF- $\alpha$, which has very similar broad effects to infliximab. ${ }^{16}$ Anti-TNF- $\alpha$ therapy produces remission in approximately one-third of patients, with many losing response over time. ${ }^{8}$ The development of newer therapies continues to be an important area of research. 


\section{Vedolizumab}

Vedolizumab is a monoclonal antibody of the integrin antagonist class of drugs developed for use in IBD. During development, it has been known variously as LDP02, MLN02, MLN0002, and vedolizumab. ${ }^{17}$

\section{Efficacy}

The inhibition of leucocyte adhesion using molecules that block the integrins $\alpha_{4} \beta_{7}$ and $\alpha_{4} \beta_{1}$ binding to their ligand MAdCAM-1 and VCAM-1, respectively, has provided an alternative target for therapy through the use of a small molecule that can act more selectively in inhibiting the inflammatory pathway. A monoclonal antibody against $\alpha_{4} \beta_{7}$ integrin was first used to demonstrate resolution of colitis in animal models in $1996 .{ }^{18}$ This was in a randomized controlled trial using cotton-top tamarin monkeys and was the first study to demonstrate efficacy of a monoclonal antibody to the $\alpha_{4} \beta_{7}$ integrin. When in captivity, the cotton-top tamarin can develop spontaneous and often chronic colitis that resembles that of UC in humans. The animals included in the study were diagnosed endoscopically and histologically with chronic colitis and assessed endoscopically and histologically on two occasions prior to receiving the infusion. Eight tamarin monkeys with chronic colitis were administered either a monoclonal antibody to the $\alpha_{4} \beta_{7}$ integrin or a nontherapeutic monoclonal antibody via intramuscular injection. Those receiving the trial intervention had improved inflammatory activity and rapidly improved stool consistency with histological response. This improvement occurred within 24-72 hours of infusion. ${ }^{19}$ The control animals showed no improvement endoscopically or histologically and had diarrhea throughout the study period.

A Phase I trial using humanized $\alpha_{4} \beta_{7}$ antibody was reported in 2000 in abstract form. ${ }^{20}$ This was a doubleblind, placebo-controlled trial involving 29 patients with moderately severe UC. Patients were included who had endoscopic evidence of UC for at least $25 \mathrm{~cm}$ from anal verge with a modified Baron grade of 2 and a Mayo score of 5 or more ${ }^{21,22}$ with at least three bowel movements per day. The median age was 38 years old and $59 \%$ were male. The median Mayo score for all patients was 10 . The majority of patients continued stable dose 5-ASA medication (86\%) and $34 \%$ of patients received oral prednisolone during the study. These doses remained unchanged throughout the study. A single dose of the humanized antibody (LDP02) was given to participants in an ascending dose, $0.15 \mathrm{mg} / \mathrm{kg}$ subcutaneously (SC), $0.15 \mathrm{mg} / \mathrm{kg}$ intravenously (IV), $0.5 \mathrm{mg} / \mathrm{kg}$ IV and $3 \mathrm{mg} / \mathrm{kg}$ IV or placebo. These were given at a ratio of 5:2 for each group. A dose of $0.5 \mathrm{mg} / \mathrm{kg}$ was found sufficient to completely saturate the antibody receptors, and an endoscopic response at day 30 was reported as at least a two-grade improvement in the modified Baron score. Results are shown in Table 1.

Complete endoscopic (modified Baron grade $=0$ ) and clinical remission (Mayo score $=0$ ) were seen in $40 \%$ of those patients receiving $0.5 \mathrm{mg} / \mathrm{kg}$, although this is equal to just two patients.

The efficacy of $\alpha_{4} \beta_{7}$ antibody, now named MLN02, was subsequently demonstrated in a randomized, doubleblind, placebo-controlled trial of 181 patients. ${ }^{23}$ Adult patients with active UC and either on no therapy or stable mesalazine therapy were eligible for inclusion. Active disease was defined using the UC clinical score as a score of 5-9 points, with a score of at least 1 for stool frequency or rectal bleeding and a modified Baron score of at least grade 2 on sigmoidoscopic assessment. Disease extent had to be greater than $25 \mathrm{~cm}$ from anal verge. Patients were excluded if they required oral steroids within the 4 weeks prior to inclusion, intravenous steroids within 3 months, and any immunosuppressive therapy within the preceding 3 months. Any patients with severely active disease were also ineligible. Patients were randomly assigned into one of three groups: placebo, MLN02 $0.5 \mathrm{mg} / \mathrm{kg}$, and MLN02 $2 \mathrm{mg} / \mathrm{kg}$. Each patient received two infusions, one on day 1 and one on day 29. Of the 181 patients who were randomized, 58 were assigned to receive $0.5 \mathrm{mg} / \mathrm{kg}, 60$ to $2 \mathrm{mg} / \mathrm{kg}$, and 63 to placebo. At week 6 , the primary outcome of clinical remission (defined as a UC clinical score of $0-1$ and a modified Baron grade of $0-1$ with no evidence of rectal bleeding) was significantly higher in the MLN02 groups than in the placebo group (Table 2).

Secondary outcomes of clinical response (defined as an improvement in UC clinical score improvement by at least 3 points) were significantly higher in the MLN02 groups $(0.5 \mathrm{mg} / \mathrm{kg} 66 \% ; 2 \mathrm{mg} / \mathrm{kg} 53 \%)$ than in the placebo group $(33 \% ; P=0.002)$.

Table I Results of a Phase I trial of an $\alpha_{4} \beta_{7}$ integrin antagonist involving 29 moderately severe ulcerative colitis patients ${ }^{20}$

\begin{tabular}{llllll}
\hline $\begin{array}{l}\text { Dose of LDP02 } \\
\text { (mg/kg) }\end{array}$ & $\begin{array}{l}\mathbf{0 . 1 5} \\
\mathbf{S C}\end{array}$ & $\begin{array}{l}\mathbf{0 . 1 5} \\
\text { IV }\end{array}$ & $\begin{array}{l}\mathbf{0 . 5 0} \\
\text { IV }\end{array}$ & $\begin{array}{l}\mathbf{2 . 0 0} \\
\text { IV }\end{array}$ & Placebo \\
\hline $\begin{array}{l}\text { Meaningful endoscopic } \\
\text { response (two-grade }\end{array}$ & $1 / 5$ & $0 / 5$ & $3 / 5$ & I/5 & $2 / 8$ \\
$\begin{array}{l}\text { improvement in modified } \\
\text { Baron score) }\end{array}$ & & & & & \\
\begin{tabular}{l} 
Median Mayo score \\
\hline
\end{tabular} & 7 & 10 & I & 7 & 4.5 \\
\hline
\end{tabular}

Abbreviations: IV, intravenous; SC, subcutaneous. 
Table 2 Results of a randomized controlled trial of MLN02 involving 18I patients with active ulcerative colitis (UC) ${ }^{23}$

\begin{tabular}{|c|c|c|c|c|}
\hline $\begin{array}{l}\text { Dose of MLN02 } \\
(\mathrm{mg} / \mathrm{kg})\end{array}$ & $\begin{array}{l}\text { Patients }(\mathrm{n}) \text { achieving } \\
\text { clinical remission }^{\mathrm{a}}\end{array}$ & $\begin{array}{l}\text { Patients (\%) achieving } \\
\text { clinical response }\end{array}$ & $\begin{array}{l}\text { Patients }(n) \text { achieving } \\
\text { endoscopic remission }\end{array}$ & $\begin{array}{l}\text { Patients (\%) achieving } \\
\text { endoscopic response }\end{array}$ \\
\hline Placebo & $9 / 63(14 \%)$ & $33 \%$ & $5 / 63(8 \%)$ & $48 \%$ \\
\hline $0.5 \mathrm{IV}$ & $19 / 58(33 \%) P=0.02$ & $66 \%$ & $16 / 58(28 \%)$ & $35 \%$ \\
\hline $2.0 \mathrm{IV}$ & $19 / 60(32 \%) P=0.02$ & $53 \%$ & $7 / 60(12 \%)$ & $16 \%$ \\
\hline
\end{tabular}

Notes: a Defined as a UC clinical score of 0 or I and a modified Baron score of 0 or I and no rectal bleeding; ${ }^{b}$ defined as an improvement in UC clinical score of $\geq 3$ points; 'defined as a modified Baron score of 0 ; 'defined as an improvement in modified Baron score of more than two grades.

Abbreviation: IV, intravenous.

Endoscopic remission at week 6 was achieved in $28 \%$ of those receiving $0.5 \mathrm{mg} / \mathrm{kg}$ of MLN02, $12 \%$ of those receiving $2 \mathrm{mg} / \mathrm{kg}$, and $8 \%$ of those receiving placebo. A significant $P$ value (0.007) was attained when placebo was compared with the combined MLN02 groups, although this would appear to be largely based on the remission attained in the $0.5 \mathrm{mg} / \mathrm{kg}$ group. There was also a lower median modified Baron score in the combined MLN02 groups than in the placebo group (1.0 vs $1.5 ; P=0.02)$. All groups showed an improvement in the means of their IBD questionnaire scores, suggesting an improved global quality of life in terms of their underlying disease; however, significance was only achieved in the $0.5 \mathrm{mg} / \mathrm{kg}$ MLN02 group.

The maximal serum MLN02 levels were $12.5 \pm 2.5 \mu \mathrm{g} / \mathrm{mL}$ and $52 \pm 10.4 \mu \mathrm{g} / \mathrm{mL}$ in the $0.5 \mathrm{mg} / \mathrm{kg}$ and $2 \mathrm{mg} / \mathrm{kg}$ groups, respectively. However, only eleven patients in each group had their drug levels measured. This antibody $\left(\alpha_{4} \beta_{7}\right)$ was derived from the NS0 mouse myeloma cell line. ${ }^{24}$ The long-term outcome of patients included in the trial was not reported within the study. The exclusion of patients with a colitis severity requiring escalation of treatment does not correspond to the current use of biological therapy in routine clinical practice. ${ }^{25,26}$

A further Phase II randomized controlled trial was undertaken by Parikh et al that specifically focused on the pharmacology of increasing doses of vedolizumab. ${ }^{24}$ A new formulation of vedolizumab was developed using the Chinese hamster ovary cell-based system. Inclusion criteria were age 18-70 years and a diagnosis of UC, confirmed either histopathologically or endoscopically, with a minimum disease duration of 10 years. Patients were required to undergo endoscopy with a confirmed partial Mayo score (PMS) of between 2 and 7 and continue any stable doses of medications, including those of steroids, thiopurines, and methotrexate. The study took place in eleven sites in Canada and Russia. Eligible patients were randomized to receive 2, 6 , or $10 \mathrm{mg} / \mathrm{kg}$ of the new drug or placebo. Patients received four infusions, one each on day 1, 15, 29, and 85. Patients were followed to day 253 , at which time they were eligible to enroll in an 18-month open-label safety study. Primary endpoints included disease activity using the PMS and fecal calprotectin to provide quantitative analysis of mucosal inflammation: $>50 \mu \mathrm{g} / \mathrm{g}$ demonstrated active inflammation and $>250 \mu \mathrm{g} / \mathrm{mL}$ was considered consistent with active UC. By including patients in the study with a PMS of 1-7, those patients thought to be in remission (those with a PMS $<2.5$ ) were included in the study. Eighteen patients who received vedolizumab had a PMS at baseline of $\leq 2$ (accounting for $49 \%$ of patients who received vedolizumab); therefore, in follow-up, these patients were more likely to be in remission but were unable to meet criteria for a clinical response (reduction in PMS of $\geq 2$ ). Only 23 patients were enrolled who were within the criterion of a PMS of 4-7 who were able to attain clinical remission and a clinical response. At day 43, clinical remission (patients with a PMS of 4-7 at baseline) was $58 \%$ in the vedolizumab group and $50 \%$ in the placebo group. There was no reported dose response in remission or clinical response based on the PMS. The investigators' aims were to assess clinical pharmacology, safety, and efficacy in a dose-ranging study of vedolizumab; however, the number of patients was too small to draw conclusions regarding long-term efficacy. Clinical response was reported between days 29 to 253 with a wide-ranging percentage (53\%-79\%), which nearly overlaps with that of the placebo group $(25 \%-50 \%)$. Of note, $24 \%$ of patients enrolled in the study had been hospitalized with UC in the preceding 12 months, suggesting a more aggressive disease in those patients.

As mentioned, participants in this dose-ranging study were given the option of receiving open-label vedolizumab following day 253 for a total of 2.5 years. This case series has been reported in abstract form. ${ }^{27}$ Following the completion of the randomized trial, patients were assigned to receive vedolizumab at $2 \mathrm{mg} / \mathrm{kg}$ or $6 \mathrm{mg} / \mathrm{kg}$ every eight weeks for an additional 547 days. The efficacy was assessed using the PMS and the safety, immunogenicity, and pharmacokinetics were also analyzed and reported. Of the 38 patients who received vedolizumab in the dose-ranging study, all 
continued into the open-label extension. A further 15 patients who had been in the placebo group enrolled in the extension. Eighty-one percent of these patients continued vedolizumab until day 547; five patients withdrew due to lack of efficacy and three due to adverse events. Remission rates remained between $70 \%$ and $80 \%$ in the study. The mean PMS was 4.1 (standard deviation, 1.9) pretreatment and at week 110 the mean was 0.7 (standard deviation, 1.1). There is no report of induction of the treatment-naive patients with vedolizumab and it is unclear if there were differences between the treatment-naive patients and those who received vedolizumab in the earlier study. Mucosal healing is also not reported. Further, there is also no discussion of the clinical response to dosing differences in longer-term use. However, the high rate of participation in the extended study of those who had received vedolizumab in the earlier study suggests patients' perceived tolerance and efficacy of the drug was high.

Recently, the results of the Phase III Study of Vedolizumab (MLN002) in Patients with Moderate to Severe Ulcerative Colitis (GEMINI I) study were reported..$^{28,29}$ This was a randomized, double-blind, placebo-controlled trial assessing the efficacy and safety of vedolizumab in induction therapy for UC. Unlike previous studies, this study included patients who had received first-line treatment and still achieved eligibility criteria. Patients were eligible if they had active UC, a Mayo score of $\geq 6$ and an endoscopic sub-score of $\geq 2$ despite steroids, thiopurines, and/or anti-TNF- $\alpha$ therapy. Patients were randomized to receive either vedolizumab $300 \mathrm{mg}$ IV or placebo on days 1 and 15. Baseline characteristics of the 374 patients who were randomized included a mean age of 40.5 years, with a median disease duration of 6.5 years and mean Mayo score of 8.6. Of these participants, 224 received vedolizumab and 149 received placebo. Results showed a significantly greater proportion of patients receiving vedolizumab achieved clinical response,

Table 3 Results of the GEMINI I study of vedolizumab induction therapy for ulcerative colitis ${ }^{29}$

\begin{tabular}{lllll}
\hline Endpoint & $\begin{array}{l}\text { Placebo } \\
(\mathbf{N}=149)\end{array}$ & $\begin{array}{l}\text { Vedolizumab } \\
(\mathbf{N}=\mathbf{2 2 5})\end{array}$ & Difference & P value \\
\hline $\begin{array}{l}\text { Clinical } \\
\text { response (\%) }\end{array}$ & 25.5 & 47.1 & 21.7 & $<0.000$ I \\
$\begin{array}{l}\text { Clinical } \\
\text { remission (\%) }\end{array}$ & 5.4 & 16.9 & 11.5 & 0.0009 \\
$\begin{array}{l}\text { Mucosal } \\
\text { healing (\%) }\end{array}$ & 24.8 & 40.9 & 16.1 & 0.0012 \\
$\begin{array}{l}\text { ○ 20I2. BMJ Publishing Group Ltd. Rutgeerts P. Vedolizumab induction therapy } \\
\text { for ulcerative colitis: results of GEMINI I, a randomized, placebo-controlled, } \\
\text { double-blind, multicentre phase 3 trial. Gut. 2012;2012(Supp 3):A65. }\end{array}$ &
\end{tabular}

remission, and mucosal healing. Thirty-nine percent of the intention-to-treat population had had previous anti-TNF- $\alpha$ treatment failure and clinical response and remission was higher in those receiving vedolizumab in both anti-TNF- $\alpha$ naive and previously treated patients than in those receiving placebo (Table 3).

Vedolizumab as maintenance therapy for UC was also assessed in the GEMINI I study. ${ }^{30}$ Those patients achieving clinical response after induction therapy at 0 and 2 weeks (reduction in Mayo score of $\geq 3$ points and $\geq 30 \%$ from baseline plus a decrease in rectal bleeding sub-score of $\geq 1$ point or absolute rectal bleeding sub-score of $\leq 1$ point) were randomized 1:1:1 to receive vedolizumab $300 \mathrm{mg}$ IV at 4-week intervals, vedolizumab $300 \mathrm{mg}$ IV at 8-week intervals or placebo for 46 weeks. A total of 895 patients were enrolled, of whom 373 met response criteria at 6 weeks and were randomized into maintenance groups. Results showed that a significantly greater proportion of patients who received vedolizumab achieved clinical remission and mucosal healing than those who received placebo. A significant proportion of patients in all groups received glucocorticoids at baseline; over 52 weeks, a significantly greater proportion of vedolizumab patients were receiving no further glucocorticoids than those receiving placebo. Of the intention-to-treat population, $32 \%$ had had prior anti-TNF- $\alpha$ failure and clinical response and remission were greater in those receiving vedolizumab than those receiving placebo in both TNF- $\alpha$ naïve and previously treated patients (Table 4).

A longer-term Phase III study is underway; ${ }^{31}$ those enrolled in the GEMINI I or GEMINI II trials for UC or $\mathrm{CD}$ retrospectively will have the option to enter an extended study receiving vedolizumab every 4 weeks for up to 100 weeks. The study aims to enroll 1500 patients enrolment into the study is due to be completed in November 2013.

\section{Concomitant therapy}

The use of 5-ASA medication at stable doses in participants receiving vedolizumab has been shown in all trials. Corticosteroids at stable doses have been used in some studies ${ }^{20,22}$ and one dose-ranging study looked at a small number of patients receiving concomitant thiopurine therapy (three patients) and one with methotrexate. ${ }^{23}$ Numbers were too small to comment on the effect on efficacy or development of antibodies.

\section{Immunogenicity}

Antibodies developed to vedolizumab have been reported as "human anti-human antibodies." ${ }^{11,22}$ The development of these antibodies is thought to be associated with the reduced 
Table 4 Results of the GEMINI I study of vedolizumab as maintenance therapy for ulcerative colitis ${ }^{30}$

\begin{tabular}{|c|c|c|c|c|c|}
\hline Endpoint & $\begin{array}{l}\text { Placebo } \\
(\mathbf{N}=126)\end{array}$ & $\begin{array}{l}\text { Vedolizumab } \\
8 \text { weekly } \\
(\mathbf{N}=122) \\
\end{array}$ & $\begin{array}{l}\text { Vedolizumab } \\
4 \text { weekly } \\
(\mathrm{N}=125) \\
\end{array}$ & $\begin{array}{l}\text { Difference } \\
8 \text { weeks versus placebo/ } \\
4 \text { weeks versus placebo }\end{array}$ & $P$ value \\
\hline Clinical remission, 52 weeks (\%) & 15.9 & 41.8 & 44.8 & $26.1 / 29.1$ & $<0.0001 /<0.0001$ \\
\hline Mucosal healing, 52 weeks (\%) & 19.8 & 51.6 & 56.0 & $32.0 / 36.3$ & $<0.0001 /<0.0001$ \\
\hline $\begin{array}{l}\text { Glucocorticoid-free remission } \\
\text { (in those taking oral glucocorticoids }\end{array}$ & $\begin{array}{l}(\mathrm{N}=72) \\
139\end{array}$ & $(\mathrm{~N}=70)$ & $\begin{array}{l}(\mathrm{N}=73) \\
45.2\end{array}$ & $|7.6 / 3| .4$ & $0.0120 /<0.0001$ \\
\hline
\end{tabular}

at baseline), 52 weeks (\%)

(c) 20I3. BMJ Publishing Group Ltd. Reproduced with permission from Rutgeerts P. Vedolizumab maintenance therapy for ulcerative colitis (uc): results of GEMINI I, a randomized, placebo-controlled, double-blind, multicenter phase 3 trial. Gut. 20I2;6I (Supp 3):A65.

efficacy of vedolizumab. ${ }^{21}$ There is currently no evidence that infusion reactions are related to the development of antibodies to vedolizumab. Feagan et al demonstrated that $44 \%$ of patients receiving vedolizumab developed antibodies, of those with a higher titer $(\geq 1: 125)$ of antibody, the clinical remission seen was $12 \%$ (placebo was $14 \%$ ). ${ }^{23}$ Those patients with no detectable antibodies or only a low level of detectable antibodies had a clinical remission rate of $42 \%$. A lower proportion of patients developed antibodies in the higher dose group ( $2 \mathrm{mg} / \mathrm{kg}$ vs $0.5 \mathrm{mg} / \mathrm{kg}$ ). Over 2.5 years, these were shown to have developed in three patients $(6 \%) .{ }^{27}$ This dose-related antibody response was further demonstrated in the dose-ranging study using higher doses, although numbers were small: three patients in the $2 \mathrm{mg} / \mathrm{kg}$ group and one in $6 \mathrm{mg} / \mathrm{kg}$. One of these patients demonstrated accelerated drug clearance, but the others did not.

\section{Pharmacokinetics/-dynamics}

Blockade of the $\alpha_{4} \beta_{7}$ receptors on T-lymphocytes has been shown to occur for several weeks after a single dose of vedolizumab. ${ }^{20}$ The drug concentration following the infusion has been shown to be dose related, ${ }^{21}$ with a mean maximum concentration of $12.5 \mu \mathrm{g} / \mathrm{mL}$ in those receiving $0.5 \mathrm{mg} / \mathrm{kg}$ of vedolizumab and $52.0 \mu \mathrm{g} / \mathrm{mL}$ in those receiving $2 \mathrm{mg} / \mathrm{kg}$. The serum half-life of these two doses was 9 and 12 days, respectively, and saturation of $\alpha_{4} \beta_{7}$ receptors on T-lymphocytes was $>90 \%$ at both 4 and 6 weeks following infusion. In a dose-ranging study, the serum drug concentrations increased with increasing dose, and, when regular induction infusions were used (on day 1, 15, 29 and 85), the serum half-life was between 15 and 22 days across all groups. ${ }^{24}$ This saturation of receptors has been shown to be related to the development of antibodies. Over the longer term, trough levels of vedolizumab at one infusion every 8 weeks remained steady and detectable throughout the study, with nearly full inhibition of $\alpha_{4} \beta_{7}$ receptors. ${ }^{27}$ Trough levels were dose proportional.

\section{Adverse events}

In the clinical trials reported so far, vedolizumab appears to be well tolerated and have few serious side effects. However, safety concerns raised by other members of this general class of agent have inevitably led to a focus on any potential for rare but serious adverse events.

\section{Theoretical risk of progressive multifocal leukoencephalopathy (PML)}

PML is a potentially fatal demyelinating condition affecting the central nervous system (CNS). Concerns regarding this serious side effect seen in natalizumab patients have led to further research in this area and requirements for closer monitoring. Natalizumab, a selective adhesion molecule antagonist, acts by binding to the $\alpha_{4}$ of both the $\alpha_{4} \beta_{1}$ and $\alpha_{4} \beta_{7}$ integrins and blocks the interaction of integrins to their receptors, including fibronectin, VCAM-1, and MAdCAM-1. PML has been found to occur in patients treated with natalizumab, initially when used in multiple sclerosis (MS) and later in those with $\mathrm{CD}$. Two cases (one fatal) occurred in 1869 patients receiving natalizumab and $\beta 1 \mathrm{a}$ interferon for MS over a 2-year period and a fatal case occurred in a patient receiving natalizumab for $\mathrm{CD}$. Following this, natalizumab was withdrawn in 2005. It was reintroduced into the market in 2006 with surveillance programs in place and remains licensed in the USA for CD. Since its reintroduction, 52,000 patients have received it as monotherapy, the majority for MS, and a further ten patients have since developed PML. This concern has remained throughout the development of vedolizumab. ${ }^{32}$ PML is thought to develop during immunosuppression and reactivation of the John Cunningham (JC) virus, leading to JC virus viraemia and thought to be related to the interaction of the $\alpha_{4} \beta_{1}$ integrin. Vedolizumab is thought to be more selective, or "super-selective," $33-35$ in targeting the $\alpha_{4} \beta_{7}$ integrin only and providing an improved benefit-risk profile. ${ }^{36}$ Studies in primates have shown vedolizumab is gut-tropic in primates, with no alterations in cerebrospinal fluid or opportunistic infections, 
even with highly supratherapeutic doses $(100 \mathrm{mg} / \mathrm{kg}) .{ }^{37}$ It does not influence the $\alpha_{4} \beta_{1}$ binding to VCAM-1 in the epithelial cells of the CNS. Studies comparing vedolizumab with natalizumab in primates suggest vedolizumab does not affect immune surveillance of the CNS. ${ }^{38}$ Natalizumab has also been shown to reduce white blood cells, CD4+ and CD8+ T-lymphocytes, and the CD4+:CD8+ ratio in the cerebrospinal fluid of patients with MS. In a study of a small number of healthy volunteers, participants underwent a lumbar puncture before and after a single dose of $450 \mathrm{mg}$ of vedolizumab and no difference was found in $\mathrm{CD} 4+$ and $\mathrm{CD} 8+$ or the ratio of these. ${ }^{39}$ In a large retrospective study ${ }^{40}$ that included frozen samples from over 800 participants in Phase I/II/III clinical trials for up to 2.5 years, five patients tested positive for JC virus viraemia, all of whom then tested negative at a subsequent test. There was no relationship between those who tested positive and the dose or duration of vedolizumab treatment. In another study, ${ }^{24}$ which had a "PML risk minimization programme," of the 311 patients receiving vedolizumab who had DNA for the JC virus, only one tested positive and all subsequent samples from this patient returned to undetectable. No patients were required to undergo magnetic resonance imaging or lumbar puncture for possible PML.

To date, there have been no reported cases of PML in patients treated with vedolizumab for UC or CD. ${ }^{20,23,24,27,41}$ Further, there have been no deaths attributable to vedolizumab reported in the clinical trials. The Phase I trial ${ }^{20}$ reported in 2000 showed no acute drug reactions. Headache was the most common adverse event reported in the small number of drug-treated patients. In the larger Phase II trial, Feagan et $\mathrm{al}^{23}$ reported the most common adverse event was aggravation of UC. Interestingly, this was reported in $50 \%$ of those receiving $0.5 \mathrm{mg} / \mathrm{kg}$ vedolizumab and $37 \%$ of those receiving $2 \mathrm{mg} / \mathrm{kg}$, suggesting a dose-response relationship is not present. There was no significant difference between the vedolizumab groups and the placebo group in any category of adverse event. Three severe adverse events were attributable to vedolizumab: one patient developed primary Cytomegalovirus infection, which required no treatment and another developed urticaria and mild angioedema. In the dose-ranging study, ${ }^{24}$ only two serious adverse events were reported: one patient with a history of osteoporosis developed multiple vertebral compression fractures and one patient developed an exacerbation of chronic gastroduodenitis 169 days after the last infusion. Both these events were deemed of moderate intensity and unrelated to treatment with the study drug.

Adverse events seen over a longer period have been reported to be similar to those seen in shorter studies. ${ }^{27}$ In an extended study over 547 days, $70 \%$ of participants reported at least one adverse event and 11\% reported at least one serious adverse event. ${ }^{27}$ Nineteen percent reported headache, while $17 \%$ reported nasopharyngitis. As before, worsening symptoms of UC were seen in $8 \%$. One patient required hospitalization for infective gastroenteritis and one patient had a severe infusion reaction. No other serious adverse events were seen during the extended study.

\section{Conclusion}

Vedolizumab for the management of UC has shown promising results in clinical trials, with more data expected from the most recently published studies. It has shown efficacy in patients not responding to initial therapy (glucocorticoids) and in those whom have failed anti-TNF- $\alpha$ therapy. To date, the safety profile has been favorable, even in those continuing immunosuppressant medication. The role of vedolizumab within the standard management of UC remains uncertain over the long-term; however, it may find a place as an alternative to anti-TNF- $\alpha$ therapy or in those for whom thiopurine use is contraindicated. As it has been shown to be efficacious in those who have failed anti-TNF- $\alpha$ treatment, vedolizumab may find an important role in refractory UC prior to surgical intervention.

Conventional therapies for UC are suboptimal and a significant proportion of patients continue to experience flares or chronic symptoms as well as the adverse effects of nonspecific anti-inflammatory agents such as corticosteroids. New drugs are emerging thanks to progress in technologies for the identification and production of therapeutic antibodies targeted against specific molecules involved in the immune response. Vedolizumab is a novel anti-integrin agent that shows early promise as a treatment for inducing remission in colitis.

\section{Disclosure}

$\mathrm{KB}$ has received previous educational support for conference attendance, speaker fees and/or consultancy from Abbott Laboratories, Shire Pharmaceuticals and Warner-Chilcott and has received research support previously from Abbott Laboratories. TG declares no conflicts of interest in this work.

\section{References}

1. Ordás I, Eckmann L, Talamini M, Baumgart DC, Sandborn WJ. Ulcerative colitis. Lancet. 2012;380(9853):1606-1619.

2. D'Haens G, Sandborn WJ, Feagan BG, et al. A review of activity indices and efficacy end points for clinical trials of medical therapy in adults with ulcerative colitis. Gastroenterology. 2007;132(2):763-786.

3. Dignass A, Lindsay JO, Sturm A, et al. Second European evidence-based consensus on the diagnosis and management of ulcerative colitis part 2: current management. J Crohns Colitis. 2012;6(10):991-1030.

4. Rutgeerts P, Sandborn WJ, Feagan BG, et al. Infliximab for induction and maintenance therapy for ulcerative colitis. $N$ Engl J Med. 2005; 353(23):2462-2476. 
5. Reinisch W, Sandborn WJ, Hommes DW, et al. Adalimumab for induction of clinical remission in moderately to severely active ulcerative colitis: results of a randomised controlled trial. Gut. 2011;60(6):780-787.

6. Taxonera C, Estellés J, Fernández-Blanco I, et al. Adalimumab induction and maintenance therapy for patients with ulcerative colitis previously treated with infliximab. Aliment Pharmacol Ther. 2011;33(3): 340-348.

7. McDermott E, Murphy S, Keegan D, O’Donoghue D, Mulcahy H, Doherty G. Efficacy of Adalimumab as a long term maintenance therapy in ulcerative colitis. J Crohns Colitis. Epub April 18, 2012.

8. Danese S. New therapies for inflammatory bowel disease: from the bench to the bedside. Gut. 2012;61(6):918-932.

9. Behm BW, Bickston SJ. Humanized antibody to the alpha4beta7 integrin for induction of remission in ulcerative colitis. Cochrane Database Syst Rev. 2009;1:CD007571.

10. Tilg H, Kaser A. Vedolizumab, a humanized $\mathrm{mAb}$ against the $\alpha 4 \beta 7$ integrin for the potential treatment of ulcerative colitis and Crohn's disease. Curr Opin Investig Drugs. 2010;11(11):1295-1304.

11. Souza HS, Elia CC, Spencer J, MacDonald TT. Expression of lymphocyte-endothelial receptor-ligand pairs, alpha4beta7/MAdCAM-1 and OX40/OX40 ligand in the colon and jejunum of patients with inflammatory bowel disease. Gut. 1999;45(6):856-863.

12. Arihiro S, Ohtani H, Suzuki M, et al. Differential expression of mucosal addressin cell adhesion molecule-1 (MAdCAM-1) in ulcerative colitis and Crohn's disease. Pathol Int. 2002;52(5-6):367-374.

13. Meenan J, Spaans J, Grool TA, Pals ST, Tytgat GN, van Deventer SJ. Altered expression of alpha 4 beta 7 , a gut homing integrin, by circulating and mucosal T cells in colonic mucosal inflammation. Gut. 1997;40(2):241-246.

14. Monteleone G, Caprioli F. Why are molecular mechanisms of immune activation important in IBD? Inflam Bowel Dis. 2008;14 Suppl 2: S106-S107.

15. Caviglia R, Boskoski I, Cicala M. Maintenance treatment with infliximab for the management of Crohn's disease in adults. Biologics. 2009;3:39-49.

16. Cassinotti A, Ardizzone S, Porro GB. Adalimumab for the treatment of Crohn's disease. Biologics. 2008;2(4):763-777.

17. Marshall JK. LDP-02 (Millenium). Curr Opin Investig Drugs. 2001; 2(4):502-504.

18. Hesterberg PE, Winsor-Hines D, Briskin MJ, et al. Rapid resolution of chronic colitis in the cotton-top tamarin with an antibody to a gut-homing integrin alpha 4 beta 7. Gastroenterology. 1996;111(5): 1373-1380.

19. van Assche G, Rutgeerts P. Antiadhesion molecule therapy in inflammatory bowel disease. Inflam Bowel Dis. 2002;8(4):291-300.

20. Feagan B, Macdonald J, Greenberg G, et al. An ascending dose of a humanized alpha 4 beta 7 antibody in ulcerative colitis (UC). Gastroenterology. 2000;118(4):A874.

21. Baron JH, Cornell AM, Lennard-Jones JE. Variation between observers in describing mucosal appearances in proctocolitis. BMJ. 1964;11(1):89-92.

22. Schroeder KW, Tremaine WJ, Ilstrup DM. Coated oral 5-aminoscilyclicacid therapy for mild to moderately active ulcerative colitis. New England Journal of Medicine. 1987;317(26):1625-1629.

23. Feagan BG, Greenberg GR, Wild G, et al. Treatment of ulcerative colitis with a humanized antibody to the alpha4beta7 integrin. $N$ Engl J Med. 2005;352(24):2499-2507.

Biologics: Targets \& Therapy

\section{Publish your work in this journal}

Biologics: Targets \& Therapy is an international, peer-reviewed journal focusing on the patho-physiological rationale for and clinical application of Biologic agents in the management of autoimmune diseases, cancers or other pathologies where a molecular target can be identified. This journal is indexed on PubMed Central, CAS, EMBase, Scopus
24. Parikh A, Leach T, Wyant T, et al. Vedolizumab for the treatment of active ulcerative colitis: a randomized controlled phase 2 dose-ranging study. Inflam Bowel Dis. 2011;18(8):1470-1479.

25. National Institute for Health and Clinical Excellence (NICE). Infliximab for Acute Exacerbations of Ulcerative Colitis. NICE technology appraisal guidance 163. London: NICE; 2008 [updated 2011]. Available from: http://www.nice.org.uk/nicemedia/pdf/TA163Guidance.pdf. Accessed January 22, 2013.

26. NICE. Infliximab for Subacute Manifestations of Ulcerative Colitis. NICE technology appraisal guidance 140. London: NICE; 2008. Available from: http://www.nice.org.uk/nicemedia/pdf/TA140Guidance. pdf. Accessed January 22, 2013.

27. Parikh A, Leach T, Xu J, Feagan B. P235. Long-term clinical experience with vedolizumab (VDZ) in patients with mild to moderate ulcerative colitis (UC). J Crohns Colitis. 2012;6:Supp 1, S103.

28. Feagan B, Rutgeerts P, Sands J, et al. 943b Induction therapy for ulcerative colitis: results of GEMINI I, a randomised placebo-controlled, double-blind, multicentre phase 3 trial. Gastroenterology. 2012;142(5): S160-S161.

29. Rutgeerts P. Vedolizumab induction therapy for ulcerative colitis: results of GEMINI I, a randomized, placebo-controlled, double-blind, multicentre phase 3 trial. Gut. 2012;2012(Supp 3):A65.

30. Rutgeerts P. Vedolizumab maintenance therapy for ulcerative colitis (uc): results of GEMINI I, a randomized, placebo-controlled, double-blind, multicenter phase 3 trial. Gut. 2012;61(Supp 3):A65.

31. Reichert JM. Antibody-based therapeutics to watch in 2011. MAbs. 2011;3(1):76-99.

32. Danese $S$, De La Rue SA, Gasbarrini A. Antibody to $\alpha_{4} \beta_{7}$ integrin for ulcerative colitis. N Engl J Med. 2005;355(11):1180.

33. Allen PB. Anti-adhesion molecules: is gut specificity the key for a good safety profile? Curr Drug Deliv. 2012;9(4):333-337.

34. Cohen RD. MLN-02 in IBD: is "super-selective" really super? Gastroenterology. 2006;130(6):1923-1924.

35. Soler D, Chapman T, Yang LL, Wyant T, Egan R, Fedyk ER. The binding specificity and selective antagonism of vedolizumab, an antialpha4beta7 integrin therapeutic antibody in development for inflammatory bowel diseases. J Pharmacol Exp Ther. 2009;330(3):864-875.

36. Parikh A, Fedyk E, Soler D, et al. Gastrointestinal selectivity of vedolizumab (MLN0002), a humanized monoclonal antibody to alpha4beta7 integrin: P-0025. Inflamm Bowel Dis. 2008;14:S18.

37. Fedyk ER, Wyant T, Yang LL, et al. Exclusive antagonism of the $\alpha(4)$ $\beta(7)$ integrin by vedolizumab confirms the gut-selectivity of this pathway in primates. Inflam Bowel Dis. Epub March 14, 2012.

38. Fedyk E, Csizmadia V, Shyu W, Yang L, Wyant T, Kadambi V. The gastrointestinal-selective biologic vedolizumab does not impair immune surveillance of the central nervous system in non-human primates: O-015. Inflamm Bowel Dis. 2011;17:S4-S5.

39. Milch C, Wyant T, Xu J, Kent W, Berger J, Fox IH. P234. Vedolizumab does not reduce the CD4+:CD8+ ratio in the CSF of healthy volunteers. J Crohns Colitis. 2012;6:S102-S103.

40. Parikh A, Wyant T, Clifford D, et al. 1008 No increase in JC viremia, lymphocyte count, or circulating CD34+ hematopoietic progenitor cells after treatment with vedolizumab, a humanized monoclonal antibody to $\alpha 4 \beta 7$ integrin. Gastroenterology. 2010;138(5 Suppl 1):S145-S146.

41. Feagan BG, Greenberg GR, Wild G, et al. Treatment of active Crohn's disease with MLN0002, a humanized antibody to the alpha4beta7 integrin. Clin Gastroenterol Hepatol. 2008;6(12):1370-1377.

\section{Dovepress}

and the Elsevier Bibliographic databases. The manuscript management system is completely online and includes a very quick and fair peerreview system, which is all easy to use. Visit http://www.dovepress com/testimonials.php to read real quotes from published authors. 